\title{
Using augmented reality technology improves critical thinking for low-achievement students - An example of saponification reaction
}

\author{
[ Yufang Cheng*; Meng-han Lee; Chung-Sung Yang; Pei-Yu Wu ]
}

\begin{abstract}
- or the past decade, only few studies have explored the augmented reality (AR) technology to engage with the innovative and critical thinking in the educational research area. It might be beneficial for low-achievement students to enhance their learning skills via combination of AR technology and experimental critical thinking. In this study we employ the saponification to show the benefits of the combination. During the saponification, some potential hazards and dangers exists in chemical reactions, especially for those low-achievement students. Thus, the use of developed augmented reality learning system saponification experiment (ARLS-SE) was avoided these potential hazards and dangers. The Leap Motion tool was involved for hand interaction. The ARLS-SE system is based on five critical thinking skills; i.e. explanation, analysis, assessment, reasoning, and evaluation to train participants with critical thinking skills during the operation of the system. There are 45 participants (18-20 years old) from the first year in university to involve in the experiments. The experiments include pretest, intervention, and post-test, to explore the impact and learning performance by using the ARLS-SE with critical thinking for low-achievement students. The primary results show that the participants enjoyed the operation of ARLS-SE and performed great learning effects on saponification reaction, and significant progress on cultivation of critical thinking skills.)
\end{abstract}

Keywords-augmented reality, critical thinking, cooperative/collaborative learning, simulations; virtual reality

\section{Introduction}

Learning and thinking capacities are the main targets of education. Thinking quality and IQ development mutually are affected each other, which thinking questions, reflective capacity, and critical thinking could all consequently be enhanced [1].

\section{Yufang Cheng* and Meng-han Lee}

Department of industrial education and technology,

National Changhua University of Education;

No.1 Jin-De Road, Paisha Village 500,

Changhua, Taiwan, R.O.C.

\section{Chung-Sung Yang}

Department of Applied Chemistry,

National Chia Yi University;

Chia Yi , 60004, Taiwan, R.O.C.

\section{Pei-Yu Wu}

Student psychological counseling and guidance center

National Changhua University of Education;

No.1 Jin-De Road, Paisha Village 500,

Changhua, Taiwan, R.O.C.

Similarly, Kwok, et al., [2] indicated that the guiding inquiry and cooperative discussion could establish critical and constructive thinking; this could help students to enhance their critical thinking capacity, and further advance their learning motivation and satisfaction. Recently, augmented reality (AR) technology has been widely used in different fields. AR is able to display virtual objects that are identical in real environments. The study of Cai, et al., [3] used AR technology to present a microscopic atomic structure, which showed a positive influence on low-achievement students in junior high school. Similar study also explored that using AR technology integrated the real world for normal students realizing chemical reaction is normally invisible in reality [4]. AR not only could advance learning experiences, its interactive environment was also effective for learning motivation, attitude, and degrees of reception [5]. Immediacy and feedback would affect cognition scopes of students such as their abilities toward attention, communication, and transmitting knowledge [6].

Some of studies demonstrated that AR technology were more effective for low-achievement students than highachievement students. The study indicated that the possesses of using AR technology had a positive attitude and enjoyed the probing experiences for student' learning [7]. Their study showed great influences on learning motivation for students.

\section{The aim of this study}

The study explored that the performance and impact of using AR technology to improve critical thinking for the lowachievement students, specifically in five skills of critical thinking (explanation, analysis, assessment, reasoning, and evaluation). An augmented reality learning system saponification Experiment (ARLS-SE) was thus developed in this study. This system adopted a Leap Motion tool for using hand interaction, which could help participants to explore indepth understandings in the virtual environment. Further, AR technology could represent an abstract concept in visible object, such as using a continuity of images or listed instances, e.g., the detergent of molecular structure. The subject of "Detergent" was applied in this learning system. The detergent contains lipophilic and hydrophilic; its objects are invisible with the naked eye in the decontaminating process. Usually, the molecules in chemistry are invisible and abstract, these contents are difficult to explain in described words and still images. In this regards, using AR technology with Leap Motion could help students to realize the abstract and complex invisible chemical molecular. It also provides a safe environment for processing experiment, and allows to make mistakes in the operating process. Two questions were investigated in this study:

- What is the impact of using the ARLS-SE system on low-achieving students' learning performance? 
- What is the performance of using the ARLS-SE system on the low-achieving students' critical thinking in a cooperative learning model?

\section{System development}

The ARLS-SE was based on the design principles of heightening cognition, strengthening technique, inflexibility and concision. The teaching contents were detailed in following.

\section{A. ARLS System Framework}

The ARLS-SE was designed for the teaching material of natural science developed by using the Unity authority software for a cooperative and interactive environment. The laptop computer connected with a camera and the Leap Motion. A user could operate system via the interactive system. The cards could display the virtual objects when the user used it to face the camera of the computer; so that the additional information was represented on the screen. Furthermore, the ARLS-SE system developed by using Unity authority software, and the Leap Motion primarily developed a hand tracking system with a $\mathrm{C \#}$ programming language.

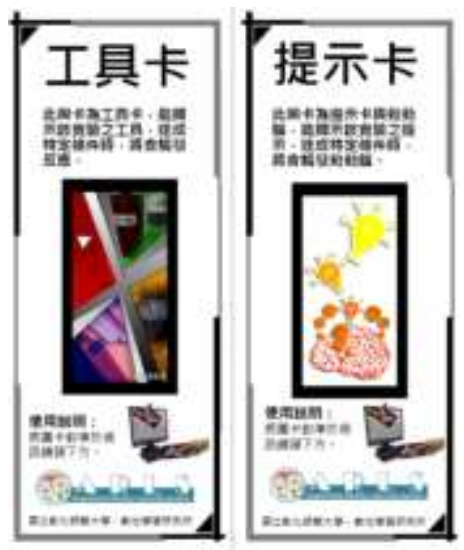

Figure 1: ARLS interaction image cards

\section{B. ARLS Teaching contents}

(a) Main menu (including six buttons, start, end, decontamination principle, saponification, grease emulsification comparison, and transesterification). (b) Principle of soap decontamination scenes (explaining the relationship between the lipophilic group and the hydrophilic group). (c) Experiment of saponification simulation scenes (accomplishing the experiment of simulating production of soap through the waving hand and contacting the interface button, and the tool box). (d) Transesterification scenes. The study questioned the research problems as follows:

\section{Participants}

Participants included 45 freshmen (18-20 years old) from the department of forestry in the university. The 22 specific low-achievement students were selected from a general chemistry course; their performing score was lower than average level in the subject of natural science saponification. The 22 low-achievement students were then divided into lowscore, middle-score, and high-score students.

\section{Operating the ARLS system}

Students could operate the ARLS-SE system for enhancing their learning motivation, which might cultivate critical thinking for these students. They could make a discussion with others via cooperative strategy of critical thinking during operating the system.

\section{E. Critical Thinking Learning Sheet (CTLS)}

The five skills of critical thinking were designed in the CTLS and referred from Facione, Sánchez, Facione, and Gainen, (1995). It included explanation (comprehending the subject and show their capability of explaining experience, data, event, judgment, rules, etc., and be able to state the meaning or importance of the subject), analysis (confirming problems, judge a concept, explain experience, connect to the relationship between information and inference, and preview thoughts ), assessment (assuming the capabilities of assessing the advantages and disadvantages of their provided answers. Regard of the open-minded thinking system, students were expected to propose the specific reasons and identify the hypothesis, meaning, and the actual effects.), reasoning (leading conclusions, hypothesis, and verify related data), and evaluation (evaluating the credibility of the supporting reasons behind the student's augments). The five skills were applied to these low-achievement students for exploring their capability of critical thinking.

\section{F. Procedure}

Three groups provided reasonable answers for the critical skills respectively, the skills included explanation, analysis, assessment, inference and evaluation. At the beginning of the experimental study, the researchers would demonstrate how to operate the ARLS-SE system within 20 minutes. The collected scores were used the CTLS for pre and post-test session. The data collection was involved descriptive calculations of group tests, the skewness was $<2$, as it was a normal distribution.

\section{Result}

The experimental study is still ongoing; we have primary findings of critical thinking after using the ARLS-SE system.

- The great influences of helping reasonable thinking in these low-achievement student was obviously by using the ARLS-SE system. Each question accounted for 10 points and full marks were 50 points (Table 1). Table 4 shows the final scores. Inter-rater reliability on Cronbach's á=0.904 showed the consistency was 
relatively higher. Each group could describe and explain clearly while using the ARLS-SE.

- The low-achievement students adopted the information provided from the system, and gave the constructed answers through a problem-solving strategy during operating the system. Specifically, the significant differences of critical skills between pre-test and posttest for each group were proofed through the pairedsample T-test. The average score of the pre-test for the three groups was 2.87, post-test average was 7.4. It showed considerable progress judging by the learning distinctiveness resulted in the paired-sample T-test (Table 2).

TABLE 1 - Scores of critical skills for each group

\begin{tabular}{|c|c|c|c|c|c|c|c|}
\hline \multirow{2}{*}{ Group } & \multirow{2}{*}{$\begin{array}{l}\text { Critical } \\
\text { skills }\end{array}$} & \multicolumn{2}{|c|}{ Evaluator 1} & \multicolumn{2}{|c|}{ Evaluator 2} & \multicolumn{2}{|c|}{ Evaluator 3} \\
\hline & & $\begin{array}{l}\text { Pre- } \\
\text { test }\end{array}$ & $\begin{array}{l}\text { Post- } \\
\text { test }\end{array}$ & $\begin{array}{l}\text { Pre- } \\
\text { test }\end{array}$ & $\begin{array}{l}\begin{array}{l}\text { Post- } \\
\text { test }\end{array} \\
\end{array}$ & $\begin{array}{l}\text { Pre- } \\
\text { test }\end{array}$ & $\begin{array}{l}\text { Post- } \\
\text { test }\end{array}$ \\
\hline \multirow{5}{*}{$\begin{array}{l}\text { Low- } \\
\text { score } \\
\text { group }\end{array}$} & Explanation & 10 & 10 & 9 & 9 & 9 & 9 \\
\hline & Analysis & 5 & 10 & 4 & 9 & 5 & 9 \\
\hline & Assessment & 3 & 7 & 4 & 7 & 4 & 7 \\
\hline & Inference & 0 & 7 & 0 & 7 & 0 & 8 \\
\hline & Evaluation & 0 & 5 & 0 & 6 & 0 & 6 \\
\hline \multirow{5}{*}{$\begin{array}{l}\text { Mid- } \\
\text { score } \\
\text { group }\end{array}$} & Explanation & 10 & 10 & 9 & 9 & 8 & 8 \\
\hline & Analysis & 5 & 5 & 4 & 4 & 4 & 4 \\
\hline & Assessment & 0 & 10 & 0 & 8 & 0 & 9 \\
\hline & Inference & 0 & 5 & 0 & 6 & 0 & 6 \\
\hline & Evaluation & 0 & 5 & 0 & 6 & 0 & 6 \\
\hline \multirow{5}{*}{$\begin{array}{l}\text { High- } \\
\text { score } \\
\text { group }\end{array}$} & Explanation & 10 & 10 & 9 & 9 & 8 & 8 \\
\hline & Analysis & 0 & 10 & 0 & 8 & 0 & 9 \\
\hline & Assessment & 0 & 7 & 0 & 7 & 0 & 7 \\
\hline & Inference & 0 & 5 & 0 & 6 & 0 & 6 \\
\hline & Evaluation & 0 & 5 & 0 & 6 & 0 & 6 \\
\hline
\end{tabular}

critical thinking, these students were able to use the skills of "analyzing the questions", "finding out the problem" and "constructing for the answer" via the group-discussions. This finding has demonstrated that using the ARLS-SE cultivating critical thinking skills has provided a more profound learning experience.

\section{Acknowledgment}

The authors would like to thank the students participated in this research by generously volunteering their time.

\section{References}

[1] Karami, M., Pakmehr, H., \& Aghili, A. (2012). Another View to Importance of Teaching Methods in Curriculum: Collaborative Learning and Students??Critical Thinking Disposition. Procedia - Social and Behavioral Sciences, 46(0), 3266-3270.

[2] Kwok, R. C. W., Ma, J., Vogel, D., \& Zhou, D. (2001). Collaborative assessment in education: an application of a fuzzy GSS. Information \& Management, 39(3), 243-253. Lee, Cheng, Y. W., Rai, S., \& Depickere, A. (2005). What affect student cognitive style in the development of hypermedia learning system? Computers \& Education, 45(1), 1-19.

[3] Cai, S., Wang, X., \& Chiang, F. K. (2014). A case study of Augmented Reality simulation system application in a chemistry course.

[4] Wu, H.-K., Lee, S. W.-Y., Chang, H.-Y., \& Liang, J.-C. (2013). Current status, opportunities and challenges of augmented reality in education. Computers \& Education, 62(0), 41-49.

[5] Ho, P. C., Chung, Szu Ming, Lin, Yi Hua (2012). Influences on children's visual cognition capabilities through playing 'intelligent matrix'developed by the augmented virtual reality technology. International Journal of Humanities and Arts Computing, 6(1-2), 160171.

[6] Bronack, S. C. (2011). The role of immersive media in online education. Journal of Continuing Higher Education, 59(2), 113-117.

[7] Facione, P. A., Facione, N. C., \& Giancarlo, C. A. (2000). The Disposition Toward Critical Thinking: Its Character, Measurement, and Relationship to Critical Thinking Skill. Informal Logic, 20(1), 61-84.

TABLE 2:

Test analysis table of CTLS average score difference between pre-test and post-test

\begin{tabular}{|c|c|c|c|c|c|c|c|}
\hline & \multicolumn{7}{|c|}{ Average scores paired sample t-test } \\
\hline & \multirow{2}{*}{$\begin{array}{l}\text { Average } \\
\text { difference }\end{array}$} & \multirow{2}{*}{$\begin{array}{l}\text { Standard } \\
\text { error of } \\
\text { the } \\
\text { difference }\end{array}$} & \multicolumn{2}{|c|}{$\begin{array}{l}\text { Confidence interval } \\
\text { of } 95 \% \text { difference }\end{array}$} & \multirow{2}{*}{$t$} & \multirow{2}{*}{$\begin{array}{l}\text { Degree } \\
\text { of } \\
\text { Freedom }\end{array}$} & \multirow{2}{*}{$\begin{array}{l}\text { Distinctiveness } \\
\text { (two-tailed) }\end{array}$} \\
\hline & & & $\begin{array}{l}\text { Lower } \\
\text { bound }\end{array}$ & $\begin{array}{l}\text { Upper } \\
\text { bound }\end{array}$ & & & \\
\hline Pre-test & .967 & 3.746 & & & & & \\
\hline Post-test & .448 & 1.734 & & & & & \\
\hline $\begin{array}{l}\text { Pretest/Post- } \\
\text { test }\end{array}$ & .828 & 3.206 & -6.353 & -2.805 & $\begin{array}{l}- \\
5.530 \\
\end{array}$ & 14 & 0.000 \\
\hline
\end{tabular}

This ARLS-SE system-simulated a learning environment provided problem-solving strategies and cooperative learning methods to cultivate the critical thinking skills for these lowachievement students. The performance of learning critical thinking skills by using the ARLS-SE system of saponification had a significant impact in these low-achievement students. Considering enhancing constructive statements of using 